\title{
Determination of Curcumin in Turmeric Sample Using Edge Plane Pyrolytic Graphite Electrode
}

\author{
Göksu Basmaz, Naciye Öztürk* \\ Faculty of Science, Department of Chemistry, Gebze Technical University, 41400 Kocaeli, Turkey \\ naciyeozturk@gtu.edu.tr \\ *Corresponding author \\ Received: 15 January 2017 \\ Accepted: 5 June 2017 \\ DOI: 10.18466/cbayarfbe.339339
}

\begin{abstract}
Phenolic compounds are an important class of the antioxidants and found in several natural products. Research on the phenolic compounds having antioxidant properties present in natural pruducts like fruits, spices and herbs are increased in recent years. Electroanalytical methods have low detection limits very short analysis time and require less budge as well. These advantages make the electroanalytical methods favorable and voltammetric analysis methods are one of the preferred methods in determination of the compounds having antioxidant properties present in different matrices. In this study, curcumin in turmeric samples were quantitatively determined by using edge plane pyrolytic graphite electrode (EPPG) and differential pulse voltammetry. Electrooxidation behaviour of curcumin was also examined by using cyclic voltammetry method. A three electrode electrochemical cell was used for voltammetric analysis. Edge plane pyrolitic graphite (EPPG), was used as working electrode, saturated calomel electrode (SCE) was used as reference electrode and Pt wire electrode was used as counter electrode in the cyclic voltamety and differential pulse voltametry studies. A linear relationship between anodic peak current and curcumin concentration was observed between $0.325 \mu \mathrm{M}$ to $1.95 \mu \mathrm{M}$ at EPPG electrode with differential pulse voltammetry. Detection limit was calculated as $0,296 \mu \mathrm{M}$ and the method successfully applied for detection of curcumin amount in a turmeric sample.
\end{abstract}

Keywords - Curcumin, Cyclic Voltammetry, Differential Pulse Voltammetry, Edge Plane Pyrolytic Graphite Electrode, Extraction, Turmeric

\begin{abstract}
1. Introduction
Curcumin is a natural phenolic compound which has antioxidant [1,2] antibacterial [3] and anti-inflammatory [4] properties. Turmeric is a curcumin-rich spice which is commonly used in Indian food and medicine [1]. In literature, there are numerous studies on separation and analysis of curcumin in spices, performed by high performance liquid chromatography (HPLC) [6-10], microemulsion electrokinetic chromatography [11,12], capillary electrophoresis[13,14], liquid chromatography coupled to mass spectroscopy (LC/MS) $[15,16]$, nuclear magnetic resonance (NMR) [16,17], infrared (IR) [17,18], raman [18], ultraviolet-visible (UV-VIS) spectroscopy $[17,19]$, fluorescence spectroscopy [20].
\end{abstract}

Electrochemical methods are known to have low detection limits up to $10^{-12} \mathrm{M}$ and they are usually faster and less ex- pensive than the spectroscopic methods [21]. These advantages make the electroanalytical methods very important in analytical chemistry. Escarpa [22] indicated that electrochemical approaches can be used for food analysis effectively. Voltammetric techniques have also been used to determine curcumin in various spices. [23-36]. Carbon electrodes are relatively low cost, chemically inert and can be used in various types of stable surface modifications [37]. Edge plane pyrolytic graphite electrode (EPPGE) is one of the carbon electrodes which has favourable background current [38], fast response due to high electron transfer rate, low passivation on repeated voltammograms and low fouling effect [39], similar electrocatalytic properties to carbon nanotubes [40] and low detection limits $[41,42]$. Banks and Compton indicated that EPPGE could be optimal electrode [43] that can be replaced for carbon nanotube modified electrodes for routine analysis without modifications $[44,45]$. Scientists still have interest in 
EPPGE for electroanalysis. Ostatná et al. [46] compared carbon, carbon paste, screen-printed, edge and basal plane pyrolytic graphite for analysis of human serum albumin and reported that EPPGE has better electroanalytical response than the other electrodes. Recently, unmodified edge plane pyrolytic electrode was used as a voltammetric $\mathrm{pH}$ sensor [47]. To the best of our knowledge, edge plane pyrolytic graphite has never been used for the electroanalytical determination of curcumin in turmeric. Various conventional methods have been used for curcumin extraction including hydro distillation and soxhlet extraction [49], pressurized hot water extraction at high temperature up to $197^{\circ} \mathrm{C}$ [50] or overnight soaking process [51]. Recent methods such as supercritical carbondioxide or microwave extraction were also used for extraction of curcumin from nat ural products [48]. On the other hand, ultrasonic extraction allows for a decrease in extraction time and temperature [52-55].

We used the EPPGE as working electrode in the cyclic voltammetry (CV) and differential pulse voltammetry (DPV) analysis of curcumin and extracted the curcumin in the turmeric samples by ultrasonic extraction method.

\section{Materials and Methods}

Curcumin (65\%), curcumin analytical standard (98\%), ethanol (99.8\%), potassium chloride (99.5\%), and hydrochloric acid (37\%) were obtained from Sigma Aldrich. and sodium bicarbonate (99.9\%) was obtained from VWR. CH Instruments electrode polishing kit was used for cleaning operations of electrodes. Chemicals were used without any further purifications. Curcuma longa rhizome powder (turmeric) was obtained from local store. A conventional three electrode electrochemical cell and CH Instruments 842B electrochemical analyser were used for voltammetric analysis. Edge plane pyrolitic graphite (d: $3 \mathrm{~mm}$ ) was used as working electrode. Saturated calomel electrode (SCE) was used as a reference electrode and a platinum wire was used as counter electrode. All solutions were degassed for 5 minutes with argon before the measurements. EPPGE was electrochemically activated with $0.1 \mathrm{M}$ bicarbonate solution until stable voltammogram was obtained after mechanical cleaning procedure. Cyclic voltammograms were recorded at a scan rate of $100 \mathrm{mVs}^{-1}$. In differential pulse voltammetry, a pulse height of $50 \mathrm{mV}$ and pulse width of $0.05 \mathrm{~s}$ were selected. All measurements were carried out at room temperature.

\subsection{Preparation of stock and supporting electrolyte so- lutions}

Curcumin is soluble in organic solvents like acetone, ethanol, dichloromethane. Wakte et al. reported that extraction with acetone is more efficient than ethanol [48]. On the other hand, GlaxoSmithKline's solvent selection guide indicates that ethanol is a more greener solvent than acetone
[56]. A stock solution of $6.5 \times 10^{-4} \mathrm{M}$ curcumin was prepared in ethanol and diluted to the required concentrations to be used as calibration standards.

It was shown that at $\mathrm{pH}>7$, curcumin alkaline degradation occurs and ferulic acid is formed together with condensation products [57]. Therefore, quantitative analysis of curcumin by DPV was performed at acidic and neutral $\mathrm{pH}$ values. 0.1M KCI solutions were used for $\mathrm{pH}$ 2. Hydrochloric acid was used to adjust desired $\mathrm{pH}$ values. $0.1 \mathrm{M}$ phosphate buffer solution was used at $\mathrm{pH} 7$ for $\mathrm{CV}$.

\subsection{Extraction of curcumin in turmeric samples}

0.5 gram turmeric powder was dissolved in $20 \mathrm{~mL}$ ethanol and placed at $55{ }^{\circ} \mathrm{C}$ in ultrasonic bath for 30 minutes. The mixture was then centrifuged at 5500 rpm for 5 minutes and the supernactant was collected. The remaining solid was extracted twice more by following the same procedure. The supernactant solutions were gathered and diluted with buffer solution to reduce the matrix effect prior to electrochemical analysis. We assumed that all the curcumin in turmeric sample were extracted after these three extraction.

\section{Results and Discussion}

\subsection{Cyclic Voltammetry of curcumin}

Electroxidation of curcumin at edge plane pyrolytic graphite electrode is an irreversible and $\mathrm{pH}$ dependent process and peak current of curcumin oxidation is strongly effected by $\mathrm{pH}$ values. Highest oxidation peak 2a shown on $\mathrm{CV}$ of $1.3 \times 10^{-4} \mathrm{M}$ curcumin solution in Figure 1 was chosen to use in quantitative analysis of curcumin by DPV. Quite high peak current values were obtained by EPPG electrode at $\mathrm{pH}$ 2. Eelectrochemical response is directly releated to the electrode material, edge sites on the surface of EPPG electrode also provide an increased peak current as response for curcumin concentration.

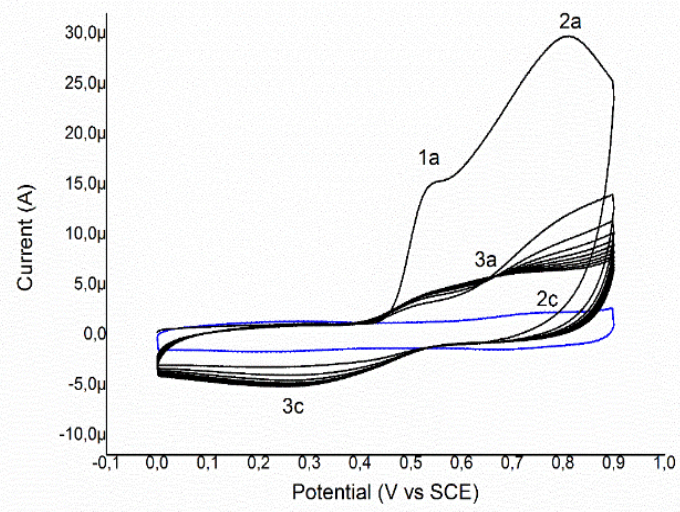

Figure 1. CV voltammogram of $1.3 \times 10^{-4} \mathrm{M}$ curcumin with EPPG electrode in $0.1 \mathrm{M} \mathrm{pH} 2 \mathrm{KCl}$ buffer. 


\subsection{Extraction and determination of curcumin in tur- meric sample}

Standard solutions of curcumin were prepared and the anodic current values were measured by DPV. (Fig. 2a) Higher current values were obtained at $\mathrm{pH} 2 \mathrm{KCI}$ solution, so it was selected for quantitative determination of curcumin. A quasi-linear relationship between anodic peak current and curcumin concentration was observed. A calibration curve was plotted between $0.325 \mu \mathrm{M}$ to $1.95 \mu \mathrm{M}$ at EPPG electrode with differential pulse voltammetry. Detection limit was calculated as $0,296 \mu \mathrm{M}$. The regression equation was ip $(\mu \mathrm{A})=3,90 \mathrm{C}-3,1 \times 10^{-7}\left(\mathrm{R}^{2}=0.9915\right)$. Detection limit was calculated according to equation of $\mathrm{C}=$ $3 \mathrm{~S}_{\mathrm{y} / \mathrm{x}} / \mathrm{b}$, (where $\mathrm{S}_{\mathrm{y} / \mathrm{x}}$ is $\mathrm{y}$ - residuals and $\mathrm{b}$ is the slope of the calibration curve) $[58,59]$.

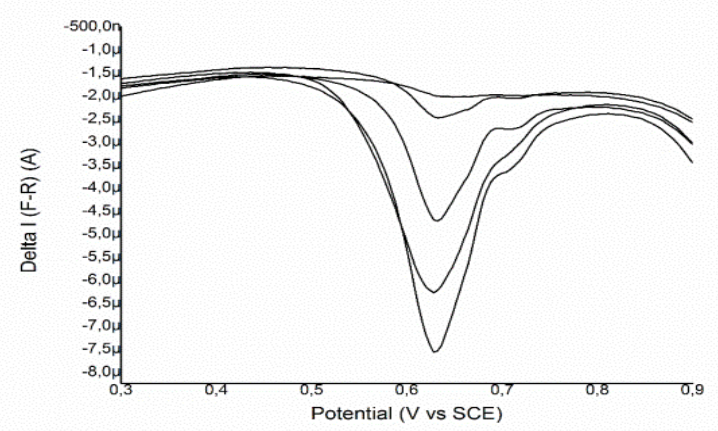

a

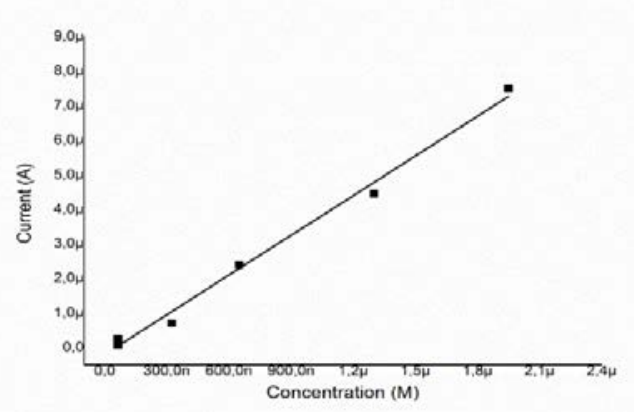

b

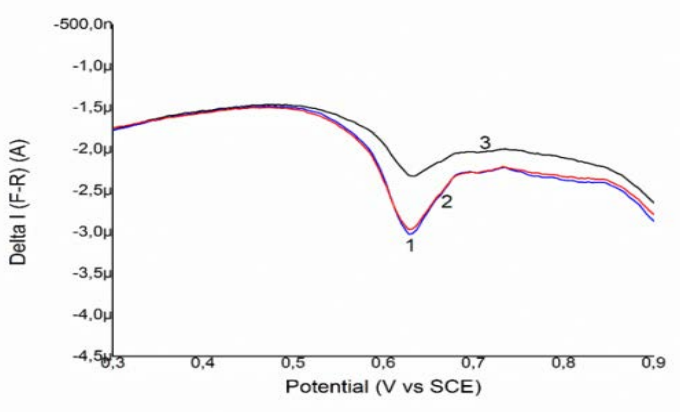

C

Figure 2. a) DPV of $6.5 \times 10^{-8} \mathrm{M}, 3.25 \times 10^{-8} \mathrm{M}, 6.5 \times 10^{-7}$ $\mathrm{M}, 1.3 \times 10^{-6} \mathrm{M}, 1.95 \times 10^{-6} \mathrm{M}, 2.6 \times 10^{-6} \mathrm{M}$ standard solutions for curcumin calibration b) Calibration curve c) DPV of turmeric extracts, (1) After first extraction $5 \mu \mathrm{L}$, (2) After second extraction $40 \mu \mathrm{L}$, (3) After third extraction $100 \mu \mathrm{L}$ added in $\mathrm{pH}$ 2, $10 \mathrm{~mL} \mathrm{KCI} \mathrm{supporting} \mathrm{electrolyte,} \mathrm{respecti-}$ vely.

Conventional soxhlet extraction, maceration and stirring are time consuming and extraction procedure of curcumin takes hours [60].

Supercritical carbondioxide extraction of curcumin [48] needs high pressure which has flow systems. Pressured hot water extraction need high temperature and pressure [50] Ultrasonic extraction has provided advantages in extraction time, temperature and solvent volume. Ultrasonic extraction process applied for turmeric reduced the extraction time to 90 minutes without any complex extraction system.

Tayyem et al [5] have analyzed different turmeric samples and explained that average curcumin content was $1.51 \%$ and reportated that their turmeric products contain $0.58 \%$ at lowest and $3.14 \%$ at highest. In this study, extraction of curcumin in the turmeric samples was repeated 3 times. It was assumed that the total amount extracted by these repeated extractions were 100 percent, hence in first, second and third extractions extraction yields were calculated as $85.8 \%, 11.5 \%$ and $2.7 \%$ respectively. Percentage amount of curcumin in the turmeric sample were found $1.03 \%$ (first extraction), $0.138 \%$ (second extraction), $0.03 \%$ (third extraction) and $1.198 \%$ as total. (Fig. 2c)

At table 1, working electrodes, electrochemical methods, working ranges and detection limits for the analysis of curcumin in the literature were given.

In literature, researchers generally selected carbon based and modified electrodes for determination of curcumin. 
Since nanoparticles or conductive polymer modified electrodes provides increase in current response while adsorptive stripping voltammetry methods, differential pulse voltammetry and square wave voltammetry provides low detection limits, modified electrode studies found in literature generally had better quantitative results than unmodified ones as expected. When we look at unmodified working electrode studies, although Gholivand et al [33] have found lower detection limits than this study, they used stripping voltammetry. In addition, HDME is not used commonly in routine analysis because of its toxicity and handling problems. This method and EPPGE electrode was successfully applied to the detection of curcumin in turmeric.

Table 1. Comparison of electrochemical response of curcumin that some of the previously reported at Literatüre

\begin{tabular}{|c|c|c|c|c|}
\hline Working electrode & $\begin{array}{c}\text { Electrochemical } \\
\text { Method }\end{array}$ & Working range $\left(\mathrm{mol} / \mathrm{L}^{-1}\right)$ & Detection Limit(M) & Reference \\
\hline \multicolumn{5}{|l|}{ Modified Electrodes } \\
\hline MWCNT/GCE & FLE-FFTSWV a & $1.0 \times 10^{-8}-1.0 \times 10^{-6}$ & $5.0 \times 10^{-9}$ & 44 \\
\hline DyNW/CPE ${ }^{b}$ & FLE-FFTSWV & $2.0 \times 10^{-9}-1.0 \times 10^{-6}$ & $5.0 \times 10^{-10}$ & 44 \\
\hline PdNps/Poly(Pr)/GE c & SWV & $5.0 \times 10^{-9}-1.0 \times 10^{-7}$ & $1.2 \times 10^{-9}$ & 45 \\
\hline Poly-ACBK/GCE d & DPV & $1.0 \times 10^{-7}-7.0 \times 10^{-5}$ & $4.1 \times 10^{-8}$ & 35 \\
\hline GR/GCE e & LSV & $5.0 \times 10^{-8}-3.0 \times 10^{-6}$ & $3 \times 10^{-8}$ & 46 \\
\hline \multicolumn{5}{|l|}{ Unmodified Electrodes } \\
\hline CPE & DPAdSV $^{\mathrm{f}}$ & $\begin{array}{c}5.76 \times 10^{-8}-4.83 \times 10^{-6} \text { and } \\
9.6 \times 10^{-7}-1.08 \times 10^{-5} \text { (for anodic peak) } \\
5.76 \times 10^{-8}-2.74 \times 10^{-6} \\
\text { (for cathodic peak) }\end{array}$ & - & 33 \\
\hline HDME & DPAdSV & $\begin{array}{l}4.95 \times 10^{-7}-2.76 \times 10^{-5} \\
9.6 \times 10^{-7}-4.84 \times 10^{-5} \\
\end{array}$ & - & 33 \\
\hline HDME & AdCSV $^{\mathrm{g}}$ & $5 \times 10^{-9}-2.8 \times 10^{-7}$ & $1.5 \times 10^{-9}$ & 39 \\
\hline GCE & $\mathrm{CV}$ & $9.9 \times 10^{-6}-1.07 \times 10^{-4}$ & $4.1 \times 10^{-6}$ & 38 \\
\hline Carbon-SPE & AdSV & $2.2 \times 10^{-6}-2.8 \times 10^{-4}$ & $4.9 \times 10^{-6}$ & 37 \\
\hline EPPGE & DPV & $3.25 \times 10^{-7}-1.95 \times 10^{-6}$ & $2.96 \times 10^{-7}$ & This work \\
\hline
\end{tabular}

a) FLE-FFTSWV: Flow injection electrochemical-fast Fourier transform square wave voltammetry,

b) DyNW/CPE: Dysprosium Nanowire/Carbon paste electrode,

c) PdNps/Poly(Pr)/GE: Palladium nanoparticles/ Polyproline/Graphite electrode,

d) Poly-ACBK/GCE: Poly-Acid chrome blue K/Glassy carbon electrode,

e) GR/GCE: Graphane modified glassy carbon electrode,

f) DPAdSV: Differential pulse adsorptive stripping voltammetry,

g) AdCSV: Adsorptive cathodic stripping voltammetry.

\section{Conclusions}

Electrochemical oxidation of curcumin was investigated on edge plane pyrolytic graphite by $\mathrm{CV}$ and EPPGE and shown that detailed information similar in the literature could be obtained by this working electrode which had good sensitivity for determination of low amounts of curcumin .

Ultrasonic bath extraction is readily applicable to the extraction of phenolic compounds in the natural products and provides required concentration of curcumin for voltamammetric analysis,

Differential pulse voltammetry is a powerful method for determination of micromolar concentrations and does not require preconcentration step as in the stripping methods. This method which provided high current response and low detection limit for curcumin analysis without stripping procedure or any modification of EPPG electrode,is suitable for routine analysis.

\section{Acknowledgements}

The authors thank to the GTU Chemisty Department for all the support for this research which is a part of the master thesis submitted to GTU Science Institution by Göksu Basmaz.

\section{References}

1. Aggarwal, B, B , Sundaram, C, Malani, N, Ichikawa, H, Curcumin, The Indian solid gold, Advances in Experimental Medicine and Biology, 2007, 595, 1-75.

2. Esatbeyoglu , T, Huebbe, P, Ernst, I, M, A, Chin, D, Wagner, A, E, Rimbach, G, Curcumin- From Molecule to Biological Function, Angewandte Chemie International Edition, 2012, 51, 5308-5332. 
3. Schraufstatter, E, Bernt, H, Antibacterial Action of Curcumin and Related Compounds, Nature, 1949, 164, 456-57.

4. Srimal, R, C, Dhawan, B, N, Pharmacology of diferuloyl methane (curcumin), a non-steroidal anti-inflammatory agent, Journal of Pharmacy and Pharmacology, 1973, 25, 447-452.

5. Tayyem, R, R, Heath, D, D, Al-Delaimy, W, K, Rock, C, L, Curcumin Content of Turmeric and Curry Powders, Nutrition and Cancer, 2006, 55, 126-131.

6. Smith, R, M, Witowska, B, A,Comparison of Detectors for the Determination of Curcumin in Turmeric by High-performance Liquid Chromatography, Analyst, 1984, 109, 259-261.

7. Jayaprakasha, K, Rao, L,J, Sakariah, K, K, Antioxidant activities of curcumin, demethoxycurcuminand bisdemethoxycurcumin, Food Chemistry, 2006, 98, 720-724.

8. Li, J, Jiang, Wen, Y, Fan, J, Wu, G, Y, Zhang, C, A rapid and simple HPLC method for the determination of curcumin in rat plasma, assay development, validation and application to a pharmacokinetic study of curcumin liposome, Biomedical Chromatography, 2009, 23, 1201-1207.

9. Han, Y,R, Zhu, J,J, Wang, Y,R, Wang, X,S, Liao, Y, A simple RPHPLC method for the simultaneous determination of curcumin and its prodrug, curcumin didecanoate, in rat plasma and the application to pharmacokinetic study, Biomedical Chromatography, 2011, 25 ,1144-1149.

10. Rahimi, M, Hashemi, P, Nazari, F, Cold column trapping-cloud point extraction coupled to high performance liquid chromatography for preconcentration and determination of curcumin in human urine, Analytica Chimica Acta, 2014, 826, 35-42.

11. Nhujak, T, Saisuwan, W, Srisa-art M, Petsom, A, Microemulsion electrokinetic chromatography for separation and analysis of curcumin in turmeric samples, Journal of Separation Science, 2006, 29, 666-676.

12. Li, F, Liu, R, Yang, F, Q, Xiao, W, Chen, C, Xia, Z,N, Determination of three curcumin in Curcuma longa by microemulsion electrokinetic chromatography with protective effects on the analytes, Analytical Methods, 2014, 6,8, 2566-2571.

13. Sun, $\mathrm{X}$, Gao, C,Cao, W, Yang, $\mathrm{X}$, Wang, E,Capillary electrophoresis with amperometric detection of curcumin in Chinese herbal medicine pretreated by solid-phase extraction, Journal of Chromatography A, 2002, 962, 117-125.

14. Lechtenberg, M, Quandt, B, Nahrstedt, A, Quantitative determination of curcumin in Curcuma rhizomes and rapid differentiation of Curcuma domestica Val. and Curcuma xanthorrhiza Roxb. by capillary electrophoresis, Phytochemical Analysis, 2004, 15, 152-158.

15. Jiang, H, Timmermann, B, N, Gang, D, R, Use of liquid chromatography-electrospray ionization tandem mass spectrometry to identify diarylheptanoids in turmeric (Curcuma longa L.) rhizome, Journal of Chromatography A, 2006, 1111-1121.

16. Goren, A, C, Çıkrıkçı, S, Çergel, M, Bilsel, G, Rapid quantitation of curcumin in turmeric via NMR and LC-tandem mass spectrometry, Food Chemistry, 2009, 113, 1239-1242.

17. Benassi, R, Ferrari, E, Lazzari, S, Spagnolo, F, Saladini, M, Theoretical study on Curcumin, A comparison of calculated spectroscopic properties with NMR, UV-vis and IR experimental data, Journal of Molecular Structure, 2008, 892, 168-176.
18. Mohan, P, R, K, Sreelakshmi, G, Muraleedharan, C,V, Joseph, R, Water soluble complexes of curcumin with cyclodextrins: Characterization by FT-Raman spectroscopy, Vibrational Spectroscopy, 2012, 62, 7784.

19. Erez, Y, Simkovitch, R, Shomer, S, Gepshtein, R, Huppert, D, Effect of Acid on the Ultraviolet-Visible Absorption and Emission Properties of Curcumin, Journal of Physical Chemistry A, 2014, 118, 872-884.

20. Patra, D, Barakat, C, Synchronous fluorescence spectroscopic study of solvatochromic curcumin dye, Spectrochimica Acta Part A, 2011, 79, 1034-1041.

21. Wang, J, Analytical Electrochemistry; Wiley, VCH John Wiley \& Sons Inc., 2006; pp30.

22. Escarpa, A, Food electroanalysis: sense and simplicity, The Chemical Record, 2012, 12, 72-91.

23. Stanic, Z, Voulgaropoulos, A, Girousi , S, Electroanalytical Study of the Antioxidant and Antitumor Agent Curcumin, Electroanalysis, 2008, 20 ( 11), 1263-1266.

24. Masek, A, Chrzescijanska, E, Zaborski, M, Characteristics of curcumin using cyclic voltammetry, UV-vis, fluorescence and thermogravimetric analysis, Electrochimica Acta, 2013, 107, 441-447.

25. Peng, J, Y, Nong, K, L, Cen, L, P, Electropolymerization of Acid Chrome Blue K on Glassy Carbon Electrode for the Determination of Curcumin, Journal of the Chinese Chemical Society, 2012, 59, 1415-1420.

26. Manaia, M, A, N, Diculescu, V, C, Gil, E, D, Oliveira-Brett, A, M, Guaicolic spices curcumin and capsaicin electrochemical oxidation behaviour at a glassy carbon electrode, Journal of Electroanalytical Chemistry, 2012, 682, 83-89.

27. Wray, D, M, Batchelor-McAuley, C, Compton, R, G, Selective Curcuminoid Separation and Detection via Nickel Complexation and Adsorptive Stripping Voltammetry, Electroanalysis, 2012, 24 (12), 2244-2248.

28. Ziyatdinova, G, K., Nizamova, A, M, Budnikov, H, C, Voltammetric Determination of Curcumin in Spices, Journal of Analytical Chemistry, 2012, 67, 6, 591-594.

29. Gholivand, M, B, Ahmadi, F, Pourhossein, A, Adsorptive cathodic stripping voltammetric determination of curcumin in turmeric and human serum, Collection of Czechoslovak Chemical Communications, 2011, 76, 143-157.

30. Lungu, A, Sandu, I, Boscornea, C, Tomas, S, Mihailciuc, C, Electrochemical Study of Curcumin and Bisdemetoxycurcumin on Activated Glassy Carbon Electrode, Revue Roumaine de Chimie, 2010, 55, 2, 109115.

31. Daniel, S, Limson, J, L, Dairam, A, Watkins, G, M, Daya, S, Through metal binding, curcumin protects against lead- and cadmium-induced lipid peroxidation in rat brain homogenates and against lead-induced tissue damage in rat brain, Journal of Inorganic Biochemistry, 2004, 98, 266-275.

32. Modi, G, Pitre, K, S, Electrochemical Analysis of Natural Chemopreventive Agent (Curcumin) in Extracted Sample and Pharmaceutical Formulation, Defence Science Journal, 2010, 60 (3), 255-258.

33. Chen, C, Xue, H, Mu, S, pH Dependence of reactive sites of curcumin possessing antioxidant activity and free radical scavenging ability studied using the electrochemical and ESR techniques: Polyaniline used as a source of the free radical, Journal of Electroanalytical Chemistry, 2014, 713, $22-27$. 
34. Daneshgar, P, Norouzi, P, Moosavi-Movahedi, A, A., Ganjali, M, R, Haghshenas, E, Dousty, F, Farhadi, M, Fabrication of carbon nanotube and dysprosium nanowire modified electrodes as a sensor for determination of curcumin, Journal of Applied Electrochemistry, 2009, 39, 1983-1992.

35. Arslan, E, Cakır, S, A novel palladium nanoparticles polyproline-modified graphite electrode and its application for determination of curcumin, Journal of Solid State Electrochemistry, 2014, 18( 6), 1611-1620.

36. Li, K, Li, Y, Yang, L, Wang, L, Y, B, The electrochemical characterization of curcumin and its selective detection in Curcuma using a graphene-modified electrode, Analytical Methods, 2014, 6, 7801-7808.

37. McCreery, R,L, Advanced Carbon Electrode Materials for Molecular Electrochemistry, Chemical Reviews, 2008, 108, 2646-2687.

38. Goyal, R, N, Chatterjee, S, Rana, A, R, S, A comparison of edge- and basal-plane pyrolytic graphite electrodes towards the sensitive determination of hydrocortisone, Talanta, 2010, 83, 149-155.

39. Patel, A, N, Tan, S, Miller, T, S, Macpherson, J,V, Unwin, P, R, Comparison and Reappraisal of Carbon Electrodes for the Voltammetric Detection of Dopamine, Analytical Chemistry, 2013, 85, 11755-11764.

40. Banks, C,E, Moore, R, R, Davies, T, J, Compton, R, G, Investigation of modified basal plane pyrolytic graphite electrodes: definitive evidence for the electrocatalytic properties of the ends of carbon nanotubes, Chemical Communications, 2004, 16, 1804-1805.

41. Kachoosangi, R, $T$, Compton, $R, G, A$ simple electroanalytical methodology for the simultaneous determination of dopamine, serotonin and ascorbic acid using an unmodified edge plane pyrolytic graphite electrode, Analytical and Bioanalytical Chemistry, 2007, 387, 2793-2800.

42. Khafaji, M, Shahrokhian, S, Ghalkhani, M, Electrochemistry of LevoThyroxin on Edge-Plane Pyrolytic Graphite Electrode: Application to Sensitive Analytical Determinations, Electroanalysis, 2011, 23 (8), 18751880.

43. Banks, C, E, Compton, R,G, New electrodes for old: from carbon nanotubes to edge plane pyrolytic graphite, Analyst, 2006, 131, 15-21.

44. Moore, R, R, Banks, C, Compton, R, G, Electrocatalytic detection of thiols using an edge plane pyrolytic graphite electrode, Analyst, 2004, 129, 755-758.

45. Banks, C, E, Compton, R, G, Exploring the electrocatalytic sites of carbon nanotubes for NADH detection: an edge plane pyrolytic graphite electrode study, The Analyst, 2005, 130,1232-1239.

46. Ostatna, V, Cernocka, H, Kurzatkowska, K, Palecek, E, Native and denatured forms of proteins can be discriminated at edge plane carbon electrodes, Analytica Chimica Acta, 2012, 735 , 31-36.

47. Lu, M, Compton, R, G, Voltammetric $\mathrm{pH}$ sensor based on an edge plane pyrolytic graphite electrode, Analyst, 2014, 139, 2397-2403.
48. Wakte, P, S, Sachin, B, S, Patil, A, A, Mohato, D, M, Band, T, H, Shinde, D, B, Optimization of Microwave, Ultra-sonic and Supercritical carbon dioxide assisted Extraction techniques for Curcumin from Curcuma longa, Separation and Purification Techniues, 2011, 79, 50-55.

49. Braga, M, E, M, Leal, P, F, Carvalho, J, E, Meireles, M, A, A, Comparison of Yield, Composition, and Antioxidant Activity of Turmeric (Curcuma longa L.) Extracts Obtained Using Various Techniques, Journal of Agricultural and Food Chemistry, 2003, 51, 6604-6611.

50. Euterpio, M, A, Cavaliere, C, Capriotti, A, L,Crescenzi, C, Extending the applicability of pressurized hot water extraction to compounds exhibiting limited water solubility by $\mathrm{pH}$ control: curcumin from the turmeric rhizom, Analytical and Bioanalytical Chemistry, 2011, 401, 2977-2985.

51. Mohankumar, S, McFarlane, J, R, An aqueous extract of Curcuma longa (turmeric) rhizomes stimulates insulin release and mimics insulin action on tissues involved in glucose homeostasis in vitro, Phytotherapy Research, 2011, 25, 3, 396-401.

52. Martins, R, M, Pereira, S, V, Siqueira, S, Salomao, W. F, Freitas, L, A, P, Curcuminoid content and antioxidant activity in spray dried microparticles containing turmeric extrac, Food Research International, 2013, $50,657-663$

53. Thongchai, W, Liawruangrath, B, Liawruangrath, S, Flow injection analysis of total curcumin in turmeric and total antioxidant capacity using 2,20-diphenyl-1-picrylhydrazyl assay, Food Chemistry, 2009, 112, 494499.

54. Wang, L, Weller, C, L, Recent advances in extraction of nutraceuticals from plants, Trends in Food Science \& Technology, 2006 , 17, 300-312.

55. Vinatoru, M, An overwiev of ultrasoncally assisted extraction of bioactive principles from herbs, Ultrasonic Sonochemistry, 2001, 8, 303-313.

56. Henderson, R, K, Jimenez-Gonzalez, C, Constable, D, J. C, Alston, S, R, Inglis, G, G, A, Fisher, G, Sherwood, J, Binks, S, P, Curzons, A, D, Expanding GSK's solvent selection guide -embedding sustainability into solvent selection starting at medicinal chemistry, Green Chemistry,2011, $13,854-862$

57. Tonnesen, H, H, Karlsen, J, Studies on Curcumin and Curcumin V. Alkaline Degradation of Curcumin, Zeitschrift für Lebensmittel-Untersuchung und Forschung, 1985, 180, 132-134.

58. Miller, J, J, Miller, J, N, Statistics for Analytical Chemistry; Ellis Horwood Series, PTR Prentice Hall, London, 1993; pp 110-117.

59. Filik, H, Avan, A, A, Aydar, S, Çetintaş, G, Determination of Acetaminophen in the Presence of Ascorbic Acid Using a Glassy Carbon Electrode Modified with Poly(Caffeic acid), International Journal of Electrochemical Science, 2014, 9, 148-160.

60. Mandal, V, Mohan, Y, Hemalatha, S, Microwave assisted extraction of curcumin by sample-solvent dual heating mechanism using Taguchi L9 orthogonal design, Journal of Pharmaceutical and Biomedical Analysis, 2008, 46, 322-327. 